\title{
On the Instability Problem in Simple Air-Sea Coupled Models with an Oceanic Surface Boundary Layer
}

\author{
By Yoshinobu Wakata \\ Faculty of Marine Science and Technology, Tokai University, Shimizu Shizuoka 424, Japan \\ (Manuscript reseived 2 November 1988, in revised form 14 February 1989)
}

\begin{abstract}
Simple air-sea coupled models have been proposed to explain the El Niño phenomena. The stability in an air-sea coupled model with an oceanic surface boundary layer introduced by Zebiak and Cane (1987) was investigated by solving the eigenvalue problem. This model is also associated with the eastward propagating unstable modes similar to the mode found by Hirst (1986). The stability was found to depend on the depth of mixed layer. The unstable mode does not appear in the western Pacific which has a deep mixed layer, even if the air-sea coupling coefficient (the heating parameter) is increased. However, the unstable mode readily appears in the central Pacific. It was found that, in addition to the Rossby mode, the Kelvin mode also becomes unstable at the limit of the advection in the model.
\end{abstract}

\section{Introduction}

The global structure of the El Niño phenomena became obvious from observations of the most prominent event $(1982 / 1983)$ in this century (Gill and Rasmusson 1983) and the following event in 1986/1987 (Bergman 1987, Barston 1987 and Nitta and Motoki, 1987). The study of air-sea interactions pointed out by Bjerknes (1969) almost two decades ago was re-examined with new insights which include the dynamics of equatorial waves.

The origin of El Niño was found to be located in the equatorial western Pacific rather than the eastern Pacific where the sea surface temperature response due to El Niño is large. It was noted that during the event in $1982 / 83$, the sea surface temperature anomaly (SSTA) which was generated in the equatorial western Pacific increased in amplitude as it migrated eastward over the span of one year. The El Niño occurred just after the arrival of the SSTA off the western coast of South America. Further, the migrating SSTA was accompanied by a region of active cumulus convection which was found in the observations of the outgoing long wave radiation (OLR) and wind anomalies. These facts show that air-sea interaction plays an important role in the occurrence of an El Niño event. Further, the structure of the eastward migrating disturbance shows the importance of equatorial waves such as the Kelvin wave.

In order to explain the growth and eastward move-

(C)1989, Meteorological Society of Japan ment of these atmospheric and oceanic disturbances, some authors have proposed simple models which include an air-sea feedback process. The results from these models were found to have included unstable modes.

The first is that developed by Philander, et. al. (1984). They employed the first baroclinic mode for the atmospheric forcing and used the shallow water equations with a reduced gravity for the ocean. They also adopted the traditional assumption that the sea surface temperature anomaly is proportional to the depth of the oceanic mixed layer. In this simple air-sea coupled model, the atmosphere is heated in proportion to the SST and the ocean is driven by the wind induced by the heating. It was found that an eastward migrating unstable mode was present in their model. Moreover, the structure of the unstable mode was similar to the structure of the $82 / 83$ El Niño event. The mechanism of the air-sea interaction instability is as follows: as heating of the atmosphere due to latent heat release in cumulus convection over the warm sea surface takes place, the surface winds blow toward the warm sea region. This results in the surface water accumulating in the warm area and the depth of the thermocline (i.e. SST) is further increased. The disturbance begins to migrate, owing to the difference in the responses on the east and west sides due to the rotation of the earth.

Further, other models have been proposed and the presence of unstable modes were found. These models are similar to that of Philander et. al., (1984) 
with the exception that the methods for prediction of the SST in the mixed layer are somewhat different. The second type of model is that of Rennick (1983) and Gill (1985), who assumed that the SST distribution is determined by advection. The Rossby mode becomes unstable in the tropical Pacific where the sea temperature profiles show that the western area of the ocean is warmer than the eastern.

The third type of model is that of Hirst (1986) which has the properties of both Rennick and Gill's models and Philander et. al.'s model. He added a heating/cooling term to the thermodynamic equation by considering the difference of the entrainment effect which is dependent on and proportional to the depth of the mixed layer. The unstable mode migrating eastward was found to be slower than that of Philander et. al.'s model.

Some numerical simulations of the El Niño phenomena using the simple air-sea coupled model have been attempted. Anderson and McCreary (1985) reproduced El Niño phenomena which occurred periodically at with interval of several years, owing to eastward migrating disturbances. The linearized version of this model is the one used by Hirst, as mentioned above. Zebiak and Cane (1987) included the upper surface Ekman boundary layer in the oceanic mixed layer. The entrainment effect, proportional to the divergence of the upper layer current (i.e. upward motion) is included in this model. In other models, the entrainment effect is not directly calculated from the divergence in the upper layer but is assumed to be dependent on the depth of the mixed layer. The atmosphere in their model is heated in proportion to the temperature of the oceanic surface layer and the heating is also proportional to the surface wind convergence based on the CISK mechanism. Also included in their model was the seasonal variation of basic atmospheric fields, which was not included in Anderson and McCreary's model. They were able to reproduce the nonperiodic occurrence of the El Niño events. Further, they have attempted to predict the occurrence of an El Niño event (Cane, et. al. (1986)).

The main purpose of this paper is to investigate which unstable modes are present or not present in the simple air-sea coupled model with an oceanic surface boundary layer proposed by Zebiak and Cane. Discussion is given as to how the above mentioned linear models are related to this model and which external parameters are essential for the appearance of unstable modes. In section 2 the model is described. In section 3 , the stability of the models is examined for the many external parameters which are related to the western and central Pacific. Section 4 is devoted to discussion and summary.

\section{Description of the Model}

This section gives a brief introduction to the basic equations following Zebiak and Cane (1987), hereafter referred to as ZC. The two layer ocean model consists of a frictional surface layer with fixed depth and a layer overlying a quasi-motionless deep layer.

\subsection{The model of the ocean}

The governing equations for each ocean layer on an equatorial $\beta$-plane are written as

$$
\begin{aligned}
& \partial \mathbf{u}_{1} / \partial t+\beta y \boldsymbol{k} \times \mathbf{u}_{1}= \\
& \quad-\nabla p_{1}+\tau / \rho H_{1}-K\left(\mathbf{u}_{1}-\mathbf{u}_{2}\right) / H_{1}-r \mathbf{u}_{1}
\end{aligned}
$$

$$
\begin{aligned}
& \begin{array}{l}
\partial \mathbf{u}_{2} / \partial t+\beta y \boldsymbol{k} \times \mathbf{u}_{2}= \\
\quad-\nabla p_{2}+K\left(\mathbf{u}_{1}-\mathbf{u}_{2}\right) / H_{2}-r \mathbf{u}_{2}
\end{array} \\
& \partial h / \partial t+H_{2} \nabla \cdot \mathbf{u}_{2}=-w_{s}-r h
\end{aligned}
$$

and

$$
w_{s}=H_{1} \nabla \cdot \boldsymbol{u}_{1},
$$

where $\boldsymbol{u}_{1}$ and $\boldsymbol{u}_{2}$ are current velocities in the frictional surface layer and the second layer, respectively. Here, $h$ is a depth anomaly of the second layer, $w_{s}$ is the entrainment velocity into the surface layer, $p_{1}$ and $p_{2}$ are the mean dynamic pressures, and $\mathrm{H}_{1}$ and $\mathrm{H}_{2}$ are the mean depth of each layer. Parameters $r=(2.5 \text { years })^{-1}$ and $K$ are frictional coefficients, and $\tau$ is the surface wind stress, which is proportional to the atmospheric wind $\tau \sim$ $\left.\rho\left(H_{1}+H_{2}\right) K_{s} \boldsymbol{U}\right)$.

Neglecting the pressure gradient and the time derivative terms, the equations governing the shear between layers 1 and 2 are written as

$$
\begin{aligned}
& r_{s} \boldsymbol{u}_{\boldsymbol{s}}+\beta y \boldsymbol{k} \times \boldsymbol{u}_{\boldsymbol{s}}=\tau / \rho H_{1}, \\
& \boldsymbol{r}_{\boldsymbol{s}}=K\left(1 / H_{1}+1 / H_{2}\right)+r,
\end{aligned}
$$

where $\boldsymbol{u}_{s}=\boldsymbol{u}_{1}-\boldsymbol{u}_{2}$ and $r_{s}=(2 \text { days })^{-1}$ (hereafter, this value is used for all calculations). The equations governing the ocean (Zebiak, 1984) are written as,

$$
\begin{aligned}
& \partial \boldsymbol{u} / \partial t+\beta y \boldsymbol{k} \times \boldsymbol{u}+g^{\prime} \nabla h=\tau / \rho H-r \boldsymbol{u}, \\
& \partial h / \partial t+H \nabla \cdot \boldsymbol{u}=0,
\end{aligned}
$$

where $\boldsymbol{u}=H^{-1}\left(H_{1} \boldsymbol{u}_{1}+H_{2} \boldsymbol{u}_{2}\right), \boldsymbol{h}=\left(H_{1} P_{1}+\right.$ $\left.H_{2} P_{2}\right) /\left(g^{\prime} H\right)$ and $H=H_{1}+H_{2}$. Values of $g^{\prime}=$ $0.056 \mathrm{~m} / \mathrm{s}^{2}, H_{1}=50 \mathrm{~m}$ and $H_{2}=100 \mathrm{~m}$ were used.

The thermodynamic equation can be written as

$$
\partial T / \partial t=-u_{1} \cdot \nabla T+M\left(w_{S}\right)\left(\frac{T-T e}{H_{1}}\right)-n T,
$$

where $M(X)$ is 


$$
M(X)=\left\{\begin{array}{cc}
X, & X>0 \\
0, & X \leq 0
\end{array}\right.
$$

Here, $T_{e}$ is the temperature of the entrainment water. The second term on the right-hand side of Eq. (9) expresses the cooling effect due to entrainment. It can affect the temperature of the surface layer only when the vertical motion is upward. $T_{e}$ can be written as

$$
T_{e}=\gamma T_{s u b}+(1-\gamma) T,
$$

where $T_{s u b}$ is the temperature of the second layer and $\gamma$ represents the mixing in the surface layer, taken as $\gamma=0.75$. It is assumed that $T_{s u b}$ can be written as

$$
T_{\text {sub }}=A(\tanh (B(\bar{h}+h))-\tanh (B \bar{h})),
$$

where $\bar{h}$ is the mean depth of the thermocline, A and $B$ indicate the amplitude and the steepness, respectively, the temperature variation in the mean profile. $T_{s u b}$ always has the same sign as the depth anomaly of the upper layer, but varies in magnitude depending on the mean depth of the thermocline. Values of $A=28^{\circ} \mathrm{C}$ and $B=0.0125 \mathrm{~m}^{-1}$ were chosen for the positive depth anomaly $(h>0)$ by $\mathrm{ZC}$.

The above equation is expanded in a Taylor's series and only the first order term is retained. By further linearizing the advection term, the following linear equation can be obtained.

$$
\begin{aligned}
& \partial T / \partial t=-\boldsymbol{u}_{1} \cdot \nabla \bar{T}-\overline{\boldsymbol{u}}_{1} \cdot \nabla T-w_{s} \bar{T}_{z} \\
& -\left(\frac{\gamma \bar{w}_{s}}{H_{1}}+n\right) T+w_{s} \frac{\gamma}{H_{1}}\left(A B / \cosh ^{2}(B \bar{h})\right) h .
\end{aligned}
$$

This equation with the exception of the term $w_{s} \bar{T}_{z}$, is very similar to the one proposed by Hirst (1986). The formulation of this term is based on the assumption that the depth of the surface layer is constant. In the model used by Hirst, the vertical heat flux directly induced by the convergence or divergence of the ocean current is not included, while in ZC's model the surface is cooled by the upward flow induced by divergent flow in the surface layer.

\subsection{The atmosphere model}

Only the first baroclinic mode is used for the atmosphere. Since the time scales for the atmosphere and ocean are quite different and present interest is only in very slow time scale motions as related to the ocean, the time derivative term can be eliminated. The governing equations can be written as

$$
\begin{aligned}
& \varepsilon U-\beta y V=-P_{x}, \\
& \varepsilon V+\beta y U=-P_{y}, \\
& \varepsilon P+C a^{2}\left(U_{x}+U_{y}\right)=-\alpha T,
\end{aligned}
$$

where $\mathrm{Ca}$ (the atmospheric free wave speed) is 60 $\mathrm{m} / \mathrm{sec}, \varepsilon$ is a damping parameter and the $e$-decaying time is 2days, Atmospheric heating is proportional to the sea surface temperature $T$, and $\alpha$ is the heating parameter.

\subsection{The eigenvalue problem}

The eigenvalue problem is solved by using a finite difference method. The variables are assumed to be symmetric with respect to the equator and have a wave like form in $X$-direction such as

$$
\begin{aligned}
& (u, v, h, T, U, V, P) \\
& \quad=\operatorname{Re}(u(y), v(y), \cdots) e^{i(k x-\sigma t)} .
\end{aligned}
$$

The basic equations can be written as

$$
\begin{aligned}
& \varepsilon U-\beta y V=-i k p, \\
& \varepsilon V+\beta y U=-P_{y}, \\
& \varepsilon P+C a^{2}\left(i k U+U_{y}\right)=-\alpha T, \\
& i \sigma u-\beta y v+g^{\prime} i k h=K_{s} U-r u, \\
& i \sigma v+\beta y u+g^{\prime} h_{y}=K_{s} V-r u, \\
& i \sigma h+H\left(i k u+v_{y}\right)=-r h, \\
& i \sigma T+u_{1} \bar{T}_{x}+\bar{u}_{1} i k T+w_{s} \bar{T}_{z} \\
& =-\left(\frac{\gamma \bar{w}_{s}}{H_{1}}+n\right) T \\
& \quad+\bar{w}_{s} \frac{\gamma}{H_{1}}\left(A B / \cosh ^{2}(B \bar{h})\right) h, \\
& u_{s}=\frac{K_{s} H\left(r_{s} U+\beta y V\right)}{H_{1}\left(\beta^{2} y^{2}+r s^{2}\right)}
\end{aligned}
$$

and

$$
v_{s}=\frac{K_{s} H\left(r_{s} V-\beta y U\right)}{H_{1}\left(\beta^{2} y^{2}+r_{s}^{2}\right)}
$$

The differential equations are then transformed into finite difference equations. In order to form a small mesh size in the equatorial region, a new meridional coordinate is formed as

$$
y^{\prime}=\sinh ^{-1}(2 y / 2500 \mathrm{~km}) \text {. }
$$

The numerical region is taken from the equator to $3411 \mathrm{~km}$ in both the north and south direction and is made up of $2 N$ grid points, with $N=20$. This results in a mesh size between each variable of 25 $\mathrm{km}$ near the equator. The variables $\left(v, V, v_{s}\right)$ and $\left(u, U, h, P, T, u_{s}\right)$ are each evaluated on a staggered grid. The variables $\left(v, V, v_{s}\right)$ are given on the equator and at the northern boundary. The boundary condition are $v_{1}=v_{n+1}=0$ at the equator and at the northern boundary. The equations from (1) to (7) can be written as 


$$
i \sigma X=L X+M Y+N Z,
$$

where $\boldsymbol{X}=\left(u_{1} \cdots u_{n} v_{2} \cdots v_{n} h_{1} \cdots h_{n} T_{1} \cdots T_{n}\right), \quad \boldsymbol{Y}$ $=\left(u_{s 1} \cdots u_{s n} v_{s 2} \cdots v_{s n}\right)$ and $Z=\left(U_{1} \cdots U_{n} V_{2} \cdots\right.$ $\left.V_{n} P_{1} \cdots P_{n}\right)$.

Equations (5), (14), (15) and (16) are written in finite difference form as

$$
\begin{aligned}
& \boldsymbol{Y}=\boldsymbol{A} \boldsymbol{Z}, \\
& \boldsymbol{B Z}=\boldsymbol{C} \boldsymbol{X} .
\end{aligned}
$$

Equations from (18) to (26) can be written for oceanic variables only as

$$
i \sigma X=\left(L+M A B^{-1} C+N B^{-1} C\right) X .
$$

The eigenvalue $\sigma$ of $\left(\boldsymbol{L}+\boldsymbol{M A B} \boldsymbol{B}^{-1} \boldsymbol{C}+\boldsymbol{N B} \boldsymbol{B}^{-1} \boldsymbol{C}\right)$ determines the stability of the system. If the imaginary part of $\sigma$ is positive, the disturbance is unstable ${ }^{1}$.

\section{Results}

The parameters for the mean depth of the thermocline, $\mathrm{h}$ and the entrainment velocity, $W$, are the determining factors for the stability of the air-sea coupled system. Parameter sets of $\left(h, W_{s}\right)$ were chosen, corresponding to the western Pacific and the central Pacific, and were used to check the stability of those regions. Further, discussion on the mechanism of the instability will be made.

\subsection{The western Pacific case}

When a value of $\bar{h}=150 \mathrm{~m}$ is used, the results show a thermocline shape typical of the western $\mathrm{Pa}$ cific. The entrainment velocity $W_{s}$ for the mean fields is induced by the basic zonal wind. The entrainment velocity $W_{s}$ near the equator can be calculated from eq. (5) and the continuity equations as

$$
W_{s} \sim \beta H_{2} \tau /\left(\rho H r_{s}{ }^{2}\right) .
$$

If the westward wind stress is assumed to be $\tau=$ $-0.5 \mathrm{dyne} / \mathrm{cm}^{2}$ due to the strong trade winds in the tropical regions, $W_{s}$ becomes $2.3 \times 10^{-5} \mathrm{~m} / \mathrm{s}(2$ $\mathrm{m} /$ day) near the equator. Neglecting the meridional variation of Ws, we used a constant value of the equator in any latitude. The damping time of the temperature of the surface layer becomes 33 days, and the coefficient $\left(K_{T}^{*}\right)$ for $h$ in the thermodynamic equation is $1.09 \times 10^{-8} \mathrm{Km}^{-1} \mathrm{~s}^{-1}$ (0.02 in the non

\footnotetext{
${ }^{1}$ This model's results were checked by comparing them to the results of Hirst (1986). When using the same parameters as in Hirst and by eliminating the second term, $M A B^{-1} C$, the model is equivalent with Hirst's model except for the time dependence of the atmosphere and the north/south boundary condition. Hirst assumed that the atmosphere is timedependent (he did not eliminate the time derivative terms in Eqs.(14), (15) and (16) and all variables are set to zero at the north/south boundary. However, it was confirmed that the difference in the growth rates and phase velocities of the modes of interest were very small.
}

dimensional unit, see for comparison Fig.5). This is three times as large as the value of $3.5 \times 10^{-9}$ $\mathrm{Km}^{-1} \mathrm{~s}^{-1}$, adopted by Hirst. The stability diagram for a wave having a wavelength of $15000 \mathrm{~km}$ is shown in Fig.1. The heating parameter, $\alpha$, which is the coefficient of $T$ in the atmospheric pressure equation (i.e. the heating parameter of the atmosphere), expresses the strength of the air-sea coupling. The value used by $Z C$ was approximately 0.38 in the present nondimensional unit. The other coupling parameter $K_{s}$ (the wind stress parameter) is set to $8.54 \times 10^{-8} s^{-1}$ which is close to the value used by Hirst $\left(8.0 \times 10^{-8} s^{-1}\right)$. The estimation of this parameter from $Z C$ is difficult, since the representative equatorial wind is necessary for linearizing the wind stress term ( $Z C$ used the time-dependent climatic wind). Thus, in the present study a typical wind of $U=4 \mathrm{~m} / \mathrm{s}$ was used in the tropics as was adopted by Hirst.

The unstable mode does not appear, even if the heating parameter is increased. The phase velocity of the Kelvin mode becomes small with increasing $\alpha$. For the case of a strong easterly wind, the damping time of the temperature in the surface layer becomes so large (e-damping time is 33 days) that the unstable mode does not appear. Further investigation in which a weaker easterly wind, approximately one forth of the previous case, results in a damping time of the temperature of the oceanic mixed layer of about 133 days. The results (not shown) indicate that the unstable mode does not appear. The damping due to entrainment becomes very weak, and the coefficient $K_{T}^{*}$ of $h$ in the thermodynamic equation becomes small, approximately $2.72 \times 10^{-9} \mathrm{Km}^{-1} \mathrm{~s}^{-1}$ $\left(K_{T}=0.005\right)$. For the unstable mode to appear, it is speculated that both a small value of damping and a large value of $K_{T}^{*}$ are necessary. This speculation was found to be correct by investigating the stability while changing $K_{T}$, as will be discussed in a later section.

\subsection{The central Pacific case}

When the depth of the mean thermocline is set to $\bar{h}=75 \mathrm{~m}$, which is a typical value for the central Pacific, the value of $K_{T}^{*}$ becomes very large, $5.6 \times$ $10^{-8} \mathrm{Km}^{-1} \mathrm{~s}^{-1}(0.102$ in non-dimensional units $\mathrm{cf}$ Fig. 7).

\section{(a) Coupling parameter}

As shown in Fig. 2, the unstable mode appears as the heating parameter is increased. The results are very similar to those of Hirsts model. However, the phase velocity of the unstable mode in comparison with the Kelvin mode is greater than that of Hirst (model III). Fig. 3 shows the unstable mode for $\alpha=1.0$. The mechanism of instability can be explained by means of the energetics, as discussed by Yamagata (1985). The oceanic current in the mixed layer, depicted in Fig. 3a and the wind in Fig. 3d are 


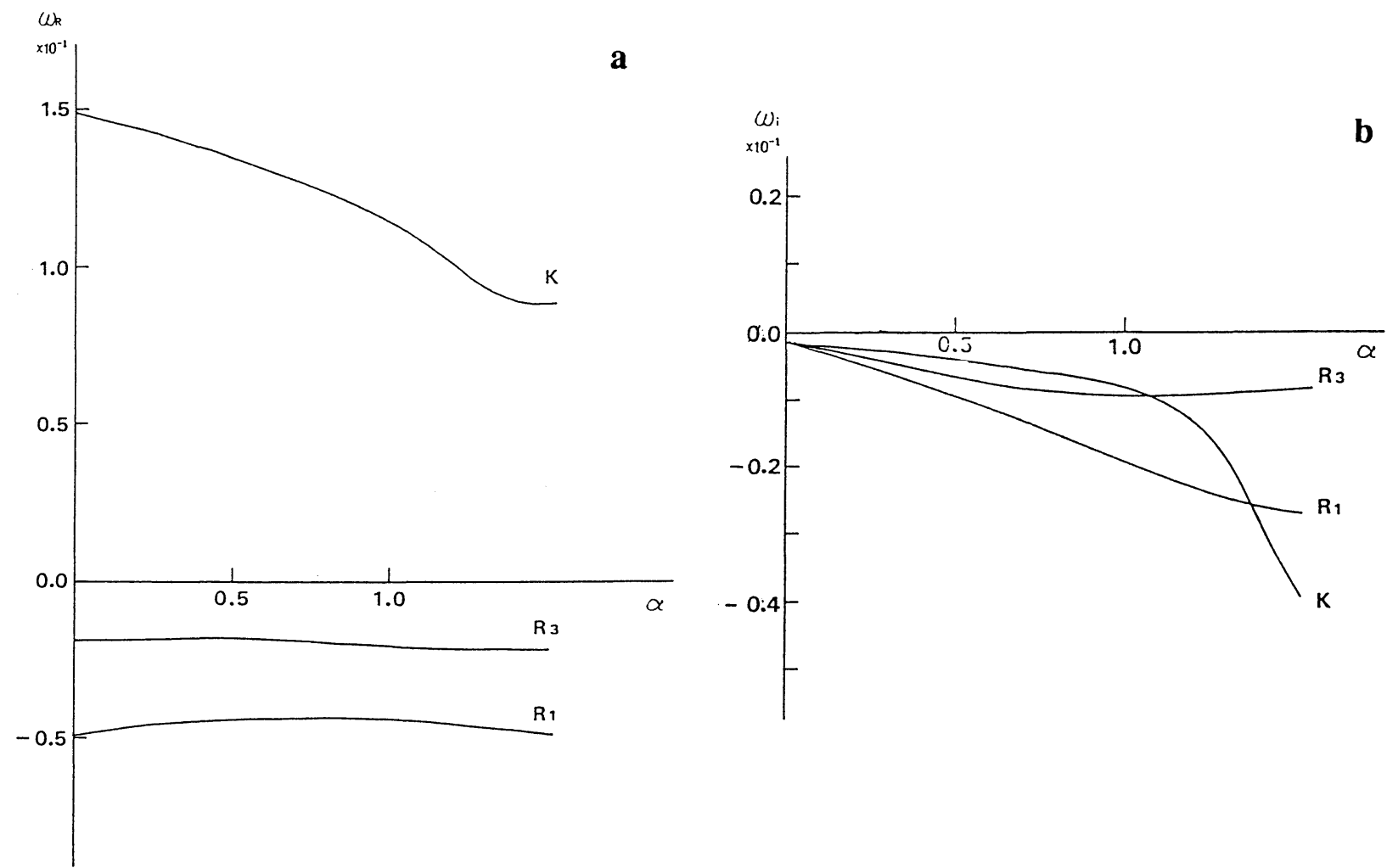

Fig. 1. Frequency (a) and growth rate (b) as a function of the heating parameter $\alpha$ for the western Pacific case $(\bar{h}=150 \mathrm{~m})$. The symbol $\mathrm{K}$ refers to the Kelvin mode, $R_{1}$ to the Rossby mode $(n=1)$ and $R_{3}$ to the Rossby mode $(n=3)$. These results (and those following) are written as dimensionless quantities. The representative time scale and length scale are 122711 (s) and $355862(\mathrm{~m})$, respectively. $\omega_{i}=0.1$ corresponds to an $e$-growing time of 142 days.

basically in the same direction, indicating that the atmospheric kinetic energy produced by the latent heat release converts rather well into oceanic kinetic energy. The oceanic currents accumulate the surface water in the areas where the sea is warm. The cooling effect due to entrainment becomes weak as a result of the increasing depth of the mixed layer, and these areas experience further warming. These processes act continuously and the unstable mode grows. The regions of upward and downward motion in the surface layer are shown in Fig. 3c. In the region of upward motion (non-dotted), the surface temperature is cooled and where there is downward motion (dotted) the surface temperature is warmed. The damped Kelvin and Rssby modes are also shown in Fig. 4 and Fig. 5, respectively. Note, in these figures, that the ocean currents and wind point in opposite directions.

\section{(b) Wavenumber dependence}

The dispersion relation is shown in Fig. 6. The growth rate of the unstable mode $U$, in Fig. $6 \mathrm{~b}$ has a peak at $k=0.12$, where the wavelength is about $18000 \mathrm{~km}$, Note that a value of $k=0.15$ (wavelength $\sim 15000 \mathrm{~km}$ ) was used in the previous calculation. The Kelvin and Rossby modes are damped over the entire wavenumber region and the unstable mode is stabilized in the short wavelength region.

\section{(c) Dependence on the mean depth of the thermo- cline (h)}

Two cases in which $\bar{h}=150 \mathrm{~m}$ and $75 \mathrm{~m}$ have been investigated, and it has been noted that the coefficient $\left(K_{T}^{*}\right)$ of $\mathrm{h}$ in the thermodynamic equation (which is dependent on $\bar{h}$ ) is an important factor for the appearance of the unstable mode. Therefore, by changing the mean depth of the mixed layer $(\bar{h})$ continuously, the stability of this model was again investigated. The results are shown in Fig.7. When $K_{T}$ is zero, the Rossby wave is unstable. However, the eastward propagating unstable mode appears as $K_{T}$ is increased. At this point, the westward propagating unstable mode does not change into a new eastward moving unstable mode directly, as shown in Fig. 7b. Note that the region where the westward propagating unstable mode is present is very narrow. A typical value of $K_{T}$ in the western Pacific is approximately 0.02 in the non dimensional unit used here, while that in the central Pacific is 0.10.

\section{(d) The advection model}

Next, the limit of $\bar{h} \rightarrow \infty$ is considered. When this occurs, $K_{T}$ approaches zero and the temperature of 

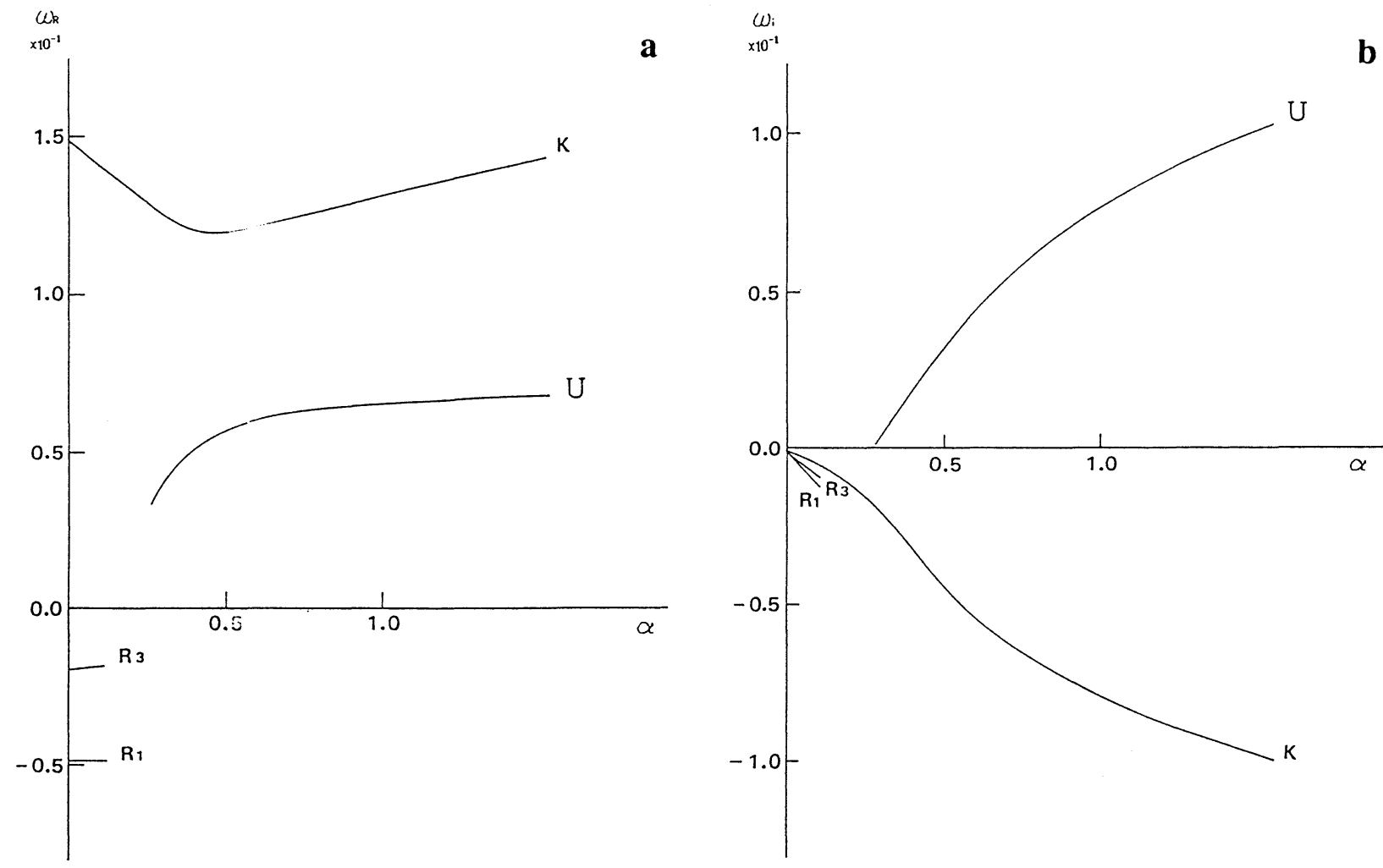

Fig. 2. As in Fig. 1 but for the central Pacific case $(\bar{h}=75 \mathrm{~m})$.
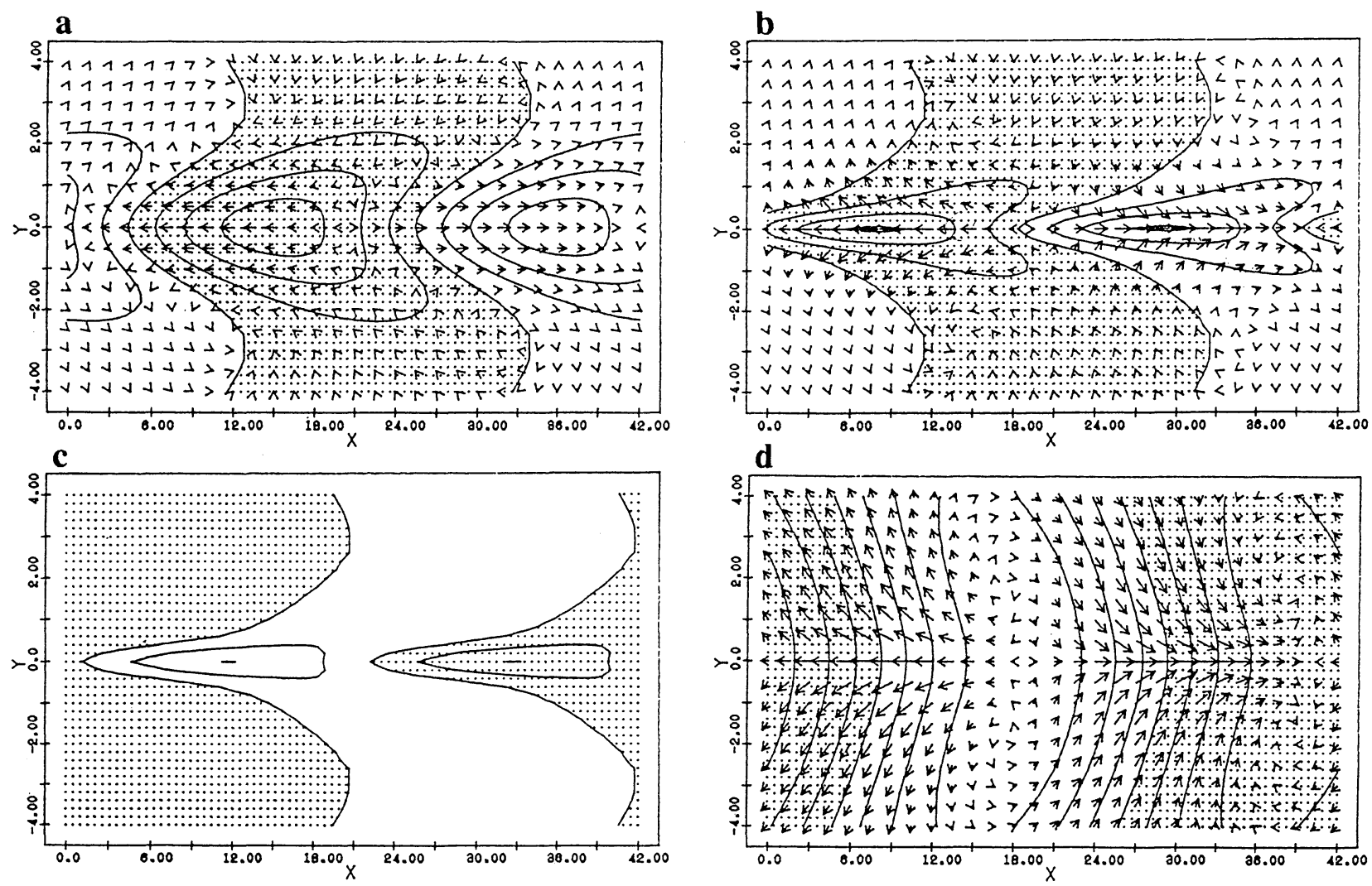

Fig. 3. The Eigenfunction of the unstable mode at $\alpha=1$. (a) the contours depict the mixed layer depth (dotted region is the negative anomaly) and vectors show the current in the mixed layer. (b) the contour and vectors depict the temperature and the current $u_{1}$ in the surface boundary layer, respectively. (c) entrainment velocity, the dotted region shows downward motion. (d) The atmospheric pressure (dotted region is negative anomaly) and surface wind vectors. 
a

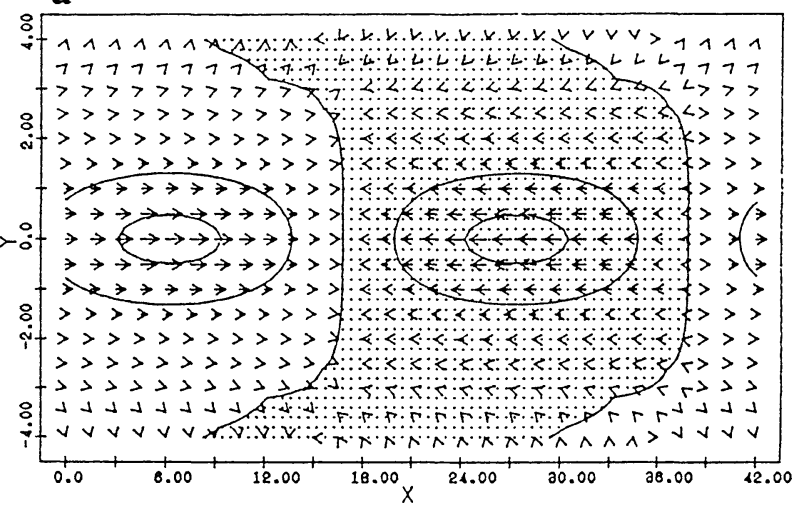

c

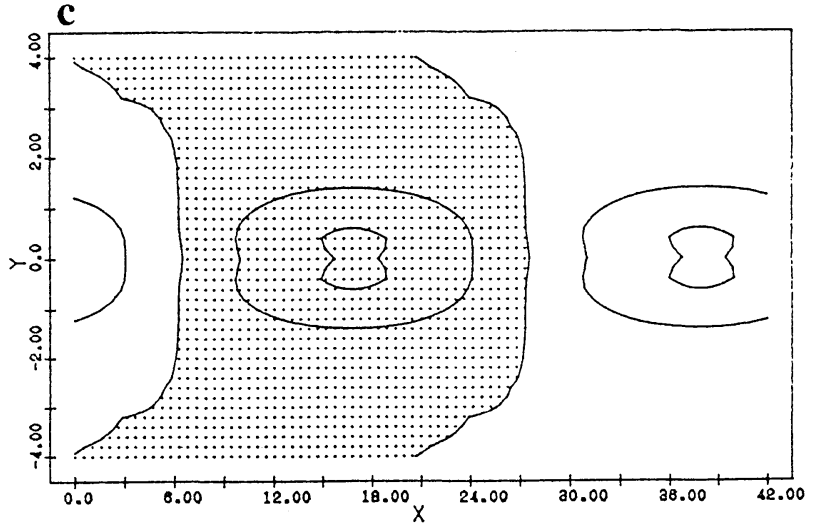

b

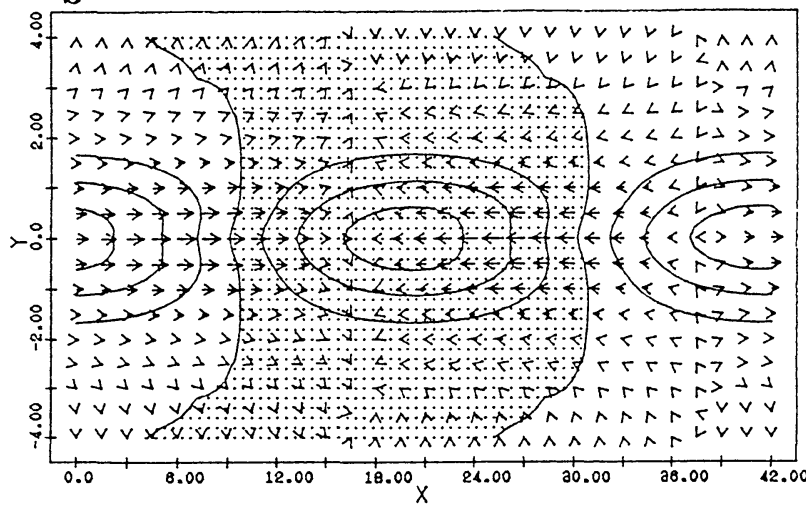

d

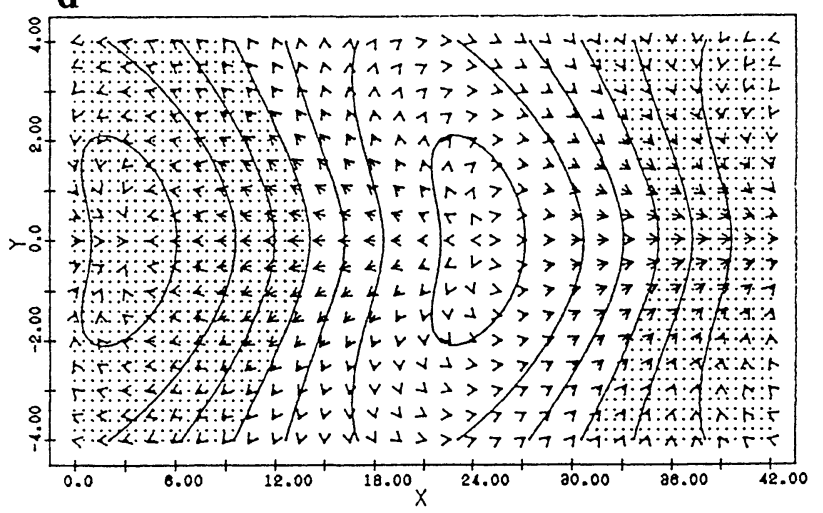

Fig. 4. As in Fig. 3 but for the damped Kelvin mode at $\alpha=0.1$.

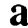
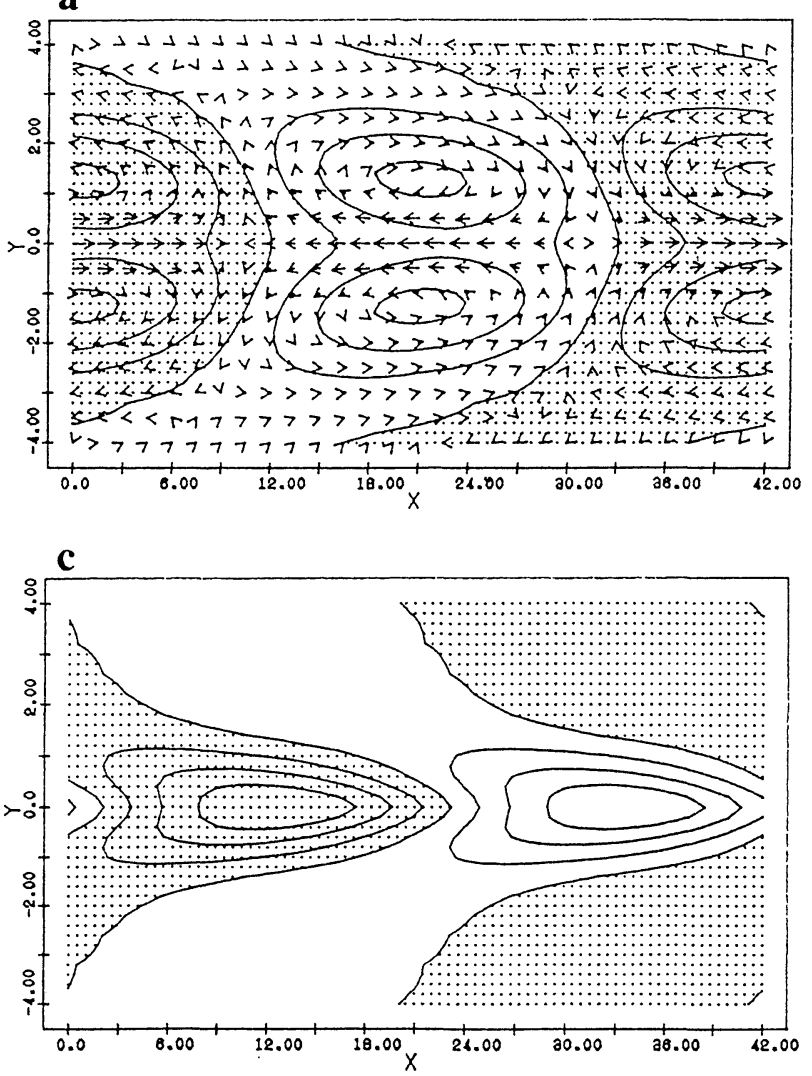

\section{b}
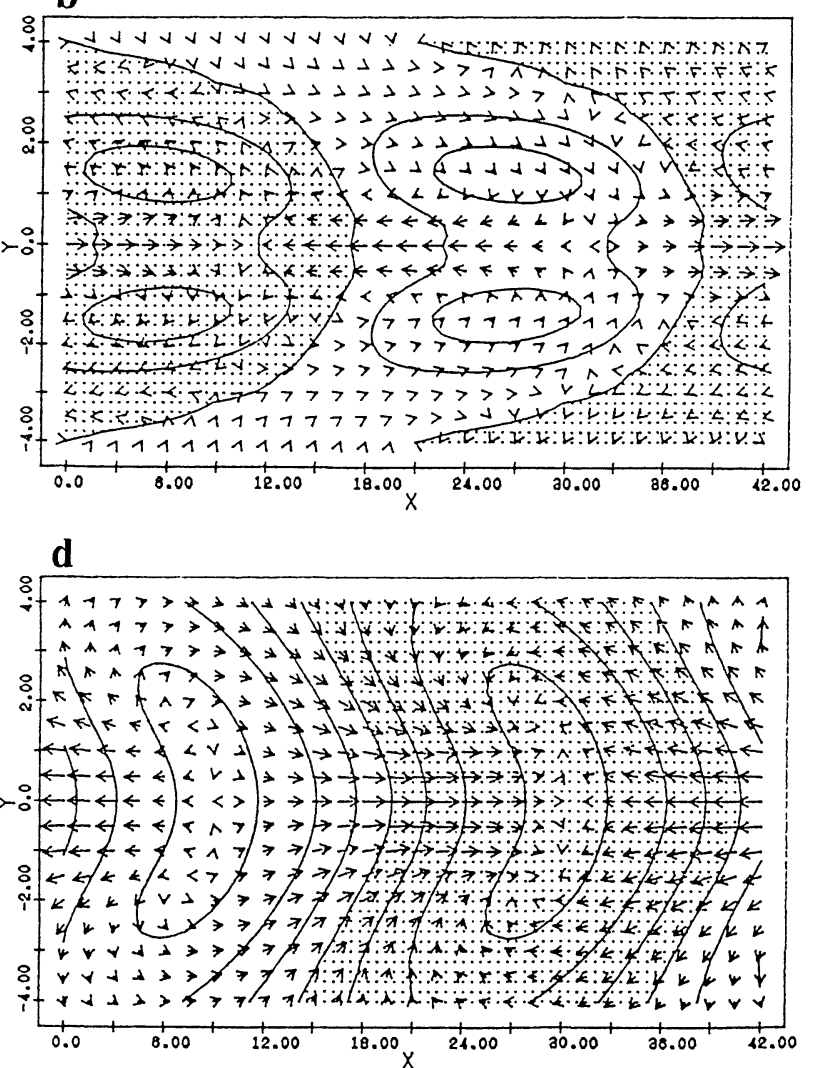

Fig. 5. As in Fig. 3 but for the damped Rossby mode $(n=1)$ at $\alpha=0.1$. 

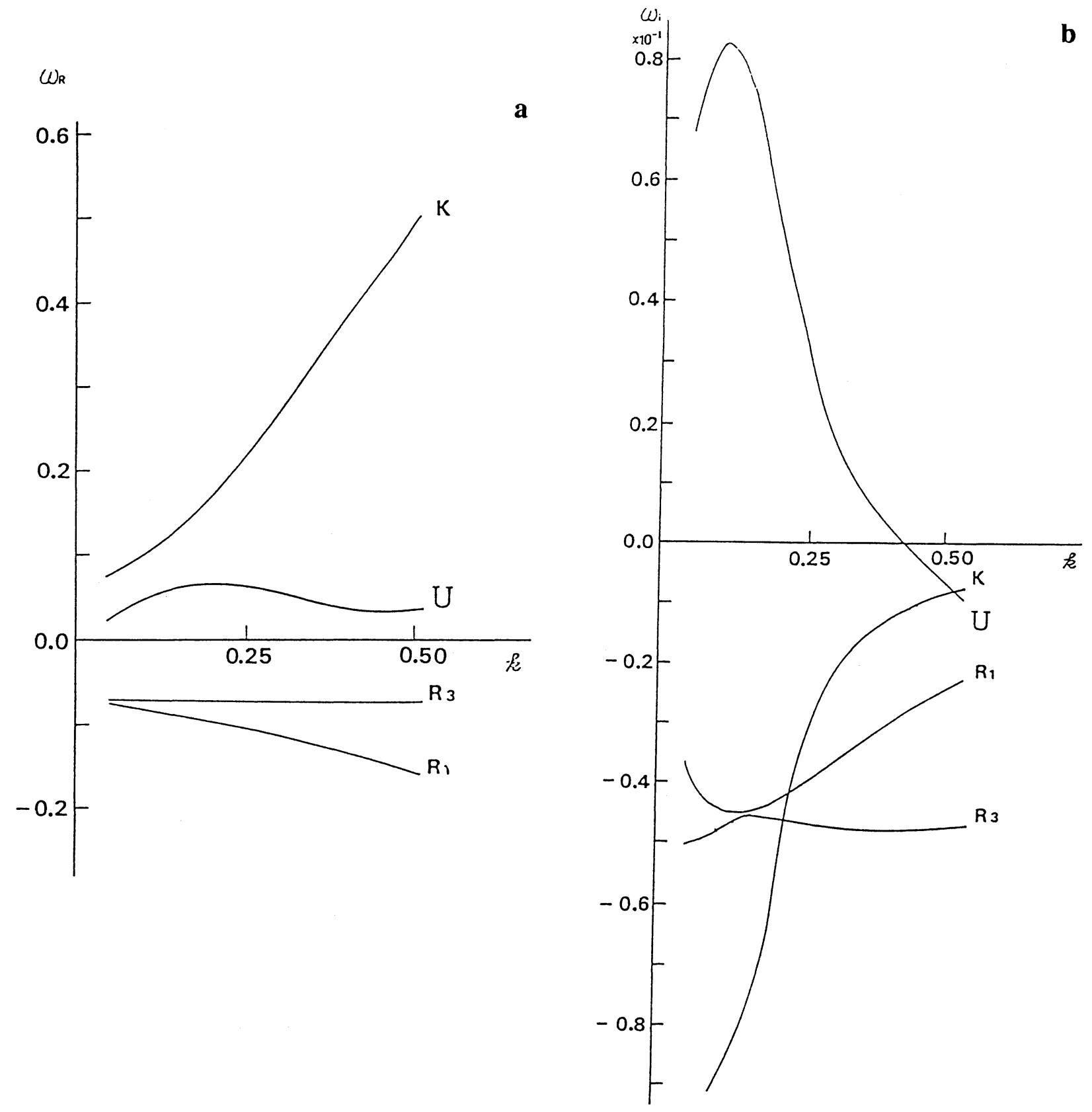

Fig. 6. Frequency (a) and growth rate (b) as function of wave number $k$ for $\bar{h}=75 \mathrm{~m}$ and $\alpha=1.0$. 

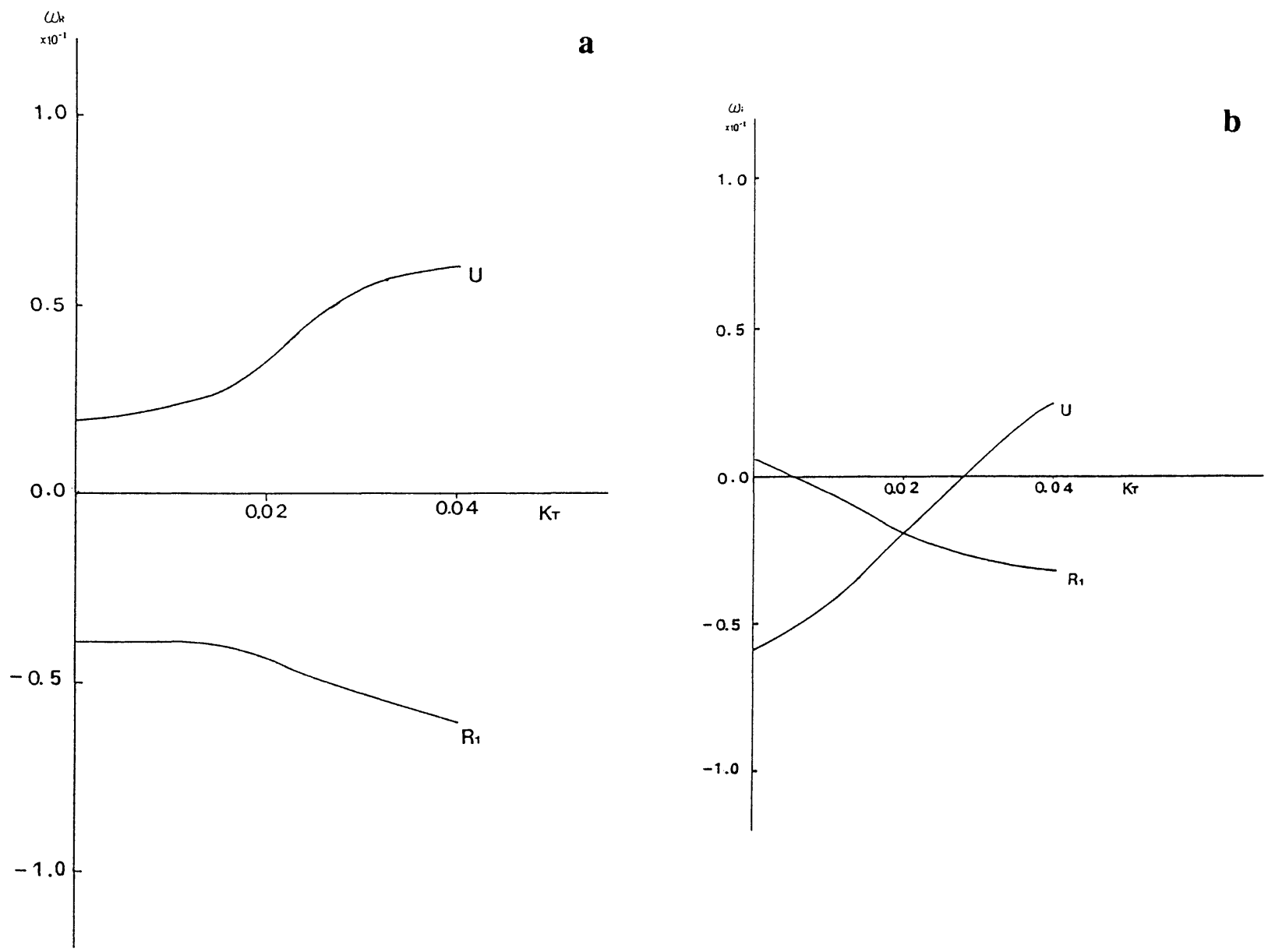

Fig. 7. Frequency (a) and growth rate (b) as a function of parameter $K_{T}$ which is the coefficient of $h$ in the thermodynamic equation (see text).

the oceanic mixed layer is determined by the effect of advection and the effect of cooling due to the upwelling motion. The model without the latter effect is equivalent to Gill's model. Fig. 8 shows the results for $W s=2 \mathrm{~m} /$ days while increasing the heating parameter $\alpha$. In this case, the Kelvin mode becomes unstable as does the Rossby mode $(n=1)$. Fig. 9 shows the structure of this unstable mode. This mode has an in phase relation between the mixed layer and temperature, contrary to the Kelvin mode in the Gill model discussed by Hirst (1985) and has a similar structure to the unstable mode in Fig.3. This unstable mode is readily stabilized by the inclusion of a small value for $K_{T}$, therefore this mode is present at the $K_{T}=0$ point in Fig.7 but not depicted.

\section{(e) Effect of the surface layer}

The essential difference between the present model and that of Hirst is that the present model includes the surface boundary layer. It is of interest to discuss how this thin surface layer affects the dispersion relation of the wave. The most important role of this layer is the cooling effect due to the up- welling flow produced by divergence in the surface layer flow. If $T z=0$, this cooling effect does not occur (cf. Eq. (13)). Therefore, an investigation as to how the dispersion relation changes as $T z$ is increased was conducted. Fig. 10 shows the growth rate and the phase velocity in the central Pacific with a weak easterly zonal wind stress of $\tau=0.1$ dyne $/ \mathrm{cm}^{2}\left(w_{s}^{*}=0.5 \mathrm{~m} /\right.$ day $)$ for three different surface layer thicknesses. The phase velocity and the growth rate are large for the thin surface layer at $\bar{T}_{z}=0$. As $\bar{T}_{z}$ increases, the growth rate shows little change but the phase velocity increases. As shown in Fig. 3c, the upwelling due to divergence in the surface layer appears on the east side of the cold area. This effect mostly assists the eastward propagation of the unstable wave.

\section{Conclusion and discussion}

The eastward propagating unstable mode was found in Zebiak and Cane's model and it resembled that of both Philander et al. and Hirst. The effect of the surface layer's divergence does not change the stability of the unstable mode to any great extent but does alter the phase speed of the wave. The crit- 

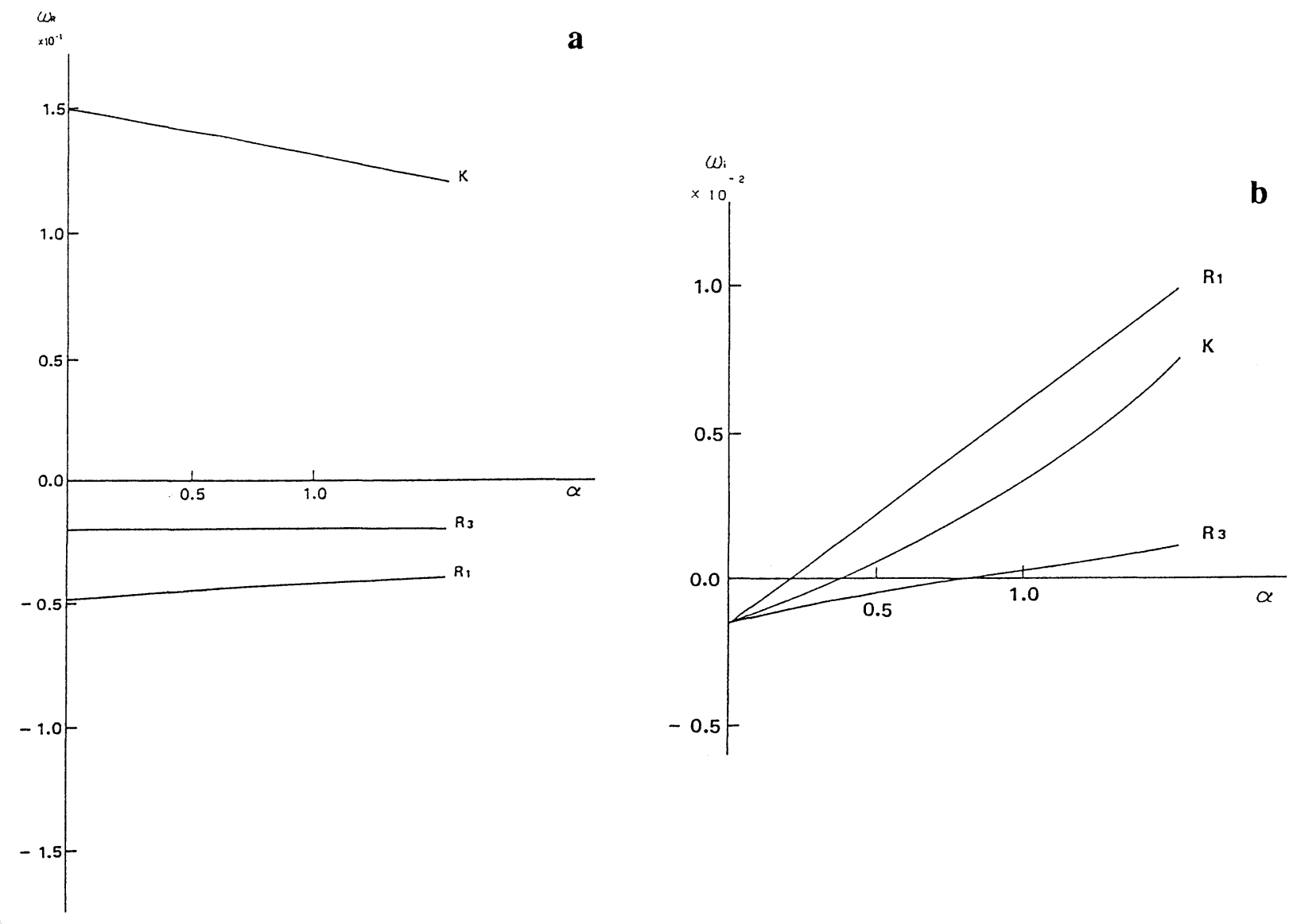

Fig. 8. Frequency (a) and growth rate (b) as a function of parameter $\alpha$ for the advection model $(\bar{h} \rightarrow \infty)$.

ical external parameter in determining the stability of the model is the coefficient $\left(K_{T}\right)$ of the mixed layer's depth in the thermodynamic equation. The growth rate of the unstable mode increases with increasing $K_{T}$. The coefficient $K_{T}$ depends on the strength of the trade winds and the parameter $\bar{h}$ which gives the vertical temperature profile of the thermocline. When the trade wind is strong, the coefficient $K_{T}$ becomes large. Simultaneously, however, the damping coefficient in th thermodynamic equation becomes large. Therefore, the appearance of strong trade winds does not always result in the generation of the unstable mode. When $\bar{h}$, the mean depth of the thermocline, is small the coefficient $K_{T}$ becomes large, i.e. the temperature of the mixed layer is easily affected by a change in the depth of the mixed layer. Therefore, in the western Pacific where $\bar{h}$ is large, the unstable mode is not generated even for large coupling parameters. Using value of $\bar{h}$ for the central Pacific, $K_{T}$ is sufficiently large and the unstable modes are present. These results are related to the sharp growth of the sea surface temperature anomaly at the date line associated with the occurrence of an El Niño event.

It was found that the Kelvin mode becomes unstable owing to the entrainment effect produced di- rectly by the divergence of surface currents in the advection model $\left(\bar{h} \rightarrow \infty\right.$ i.e. $\left.K_{T}=0\right)$ for a strong easterly zonal wind.

It should be noted that only the instability of wave like disturbances was investigated and the effects of a seasonal variation were not included in the present calculations. Therefore, the interpretation based on instability does not explain the non periodic occurrence of El Niño events and their decaying process. Even though instability is important, there are unresolved problems that affect the growing process of the waves. These remaining problems should be examined more closely in further studies.

\section{Acknowledgment}

The author would like to express his sincere thanks to Prof. Y. Sugimori and Dr. M. Kubota of Tokai University for their encouragement and valuable comments. Also, thanks are extended to Prof. $\mathrm{T}$. Yamagata of Kyushu University for exciting the authors interest in this field and valuable discussion throughout this work. The author appreciates the work of his student, Mr. H. Yamasaki, in assisting in the numerical calculations. This research was supported in part by Grant-in-Aid for Scientific 

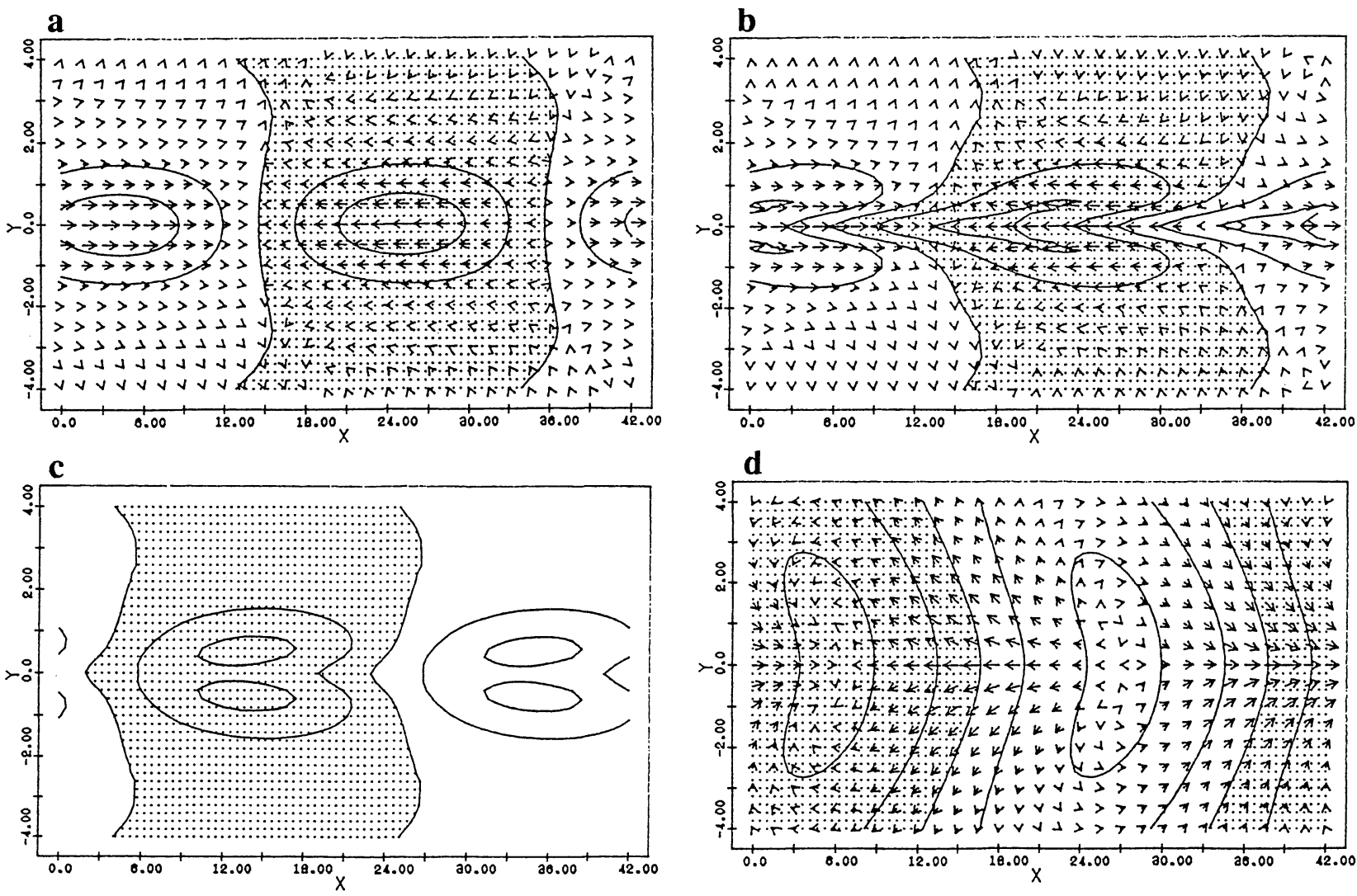

Fig. 9. As in Fig. 3 but for the unstable Kelvin mode in Fig. 8 at $\alpha=1.0$.
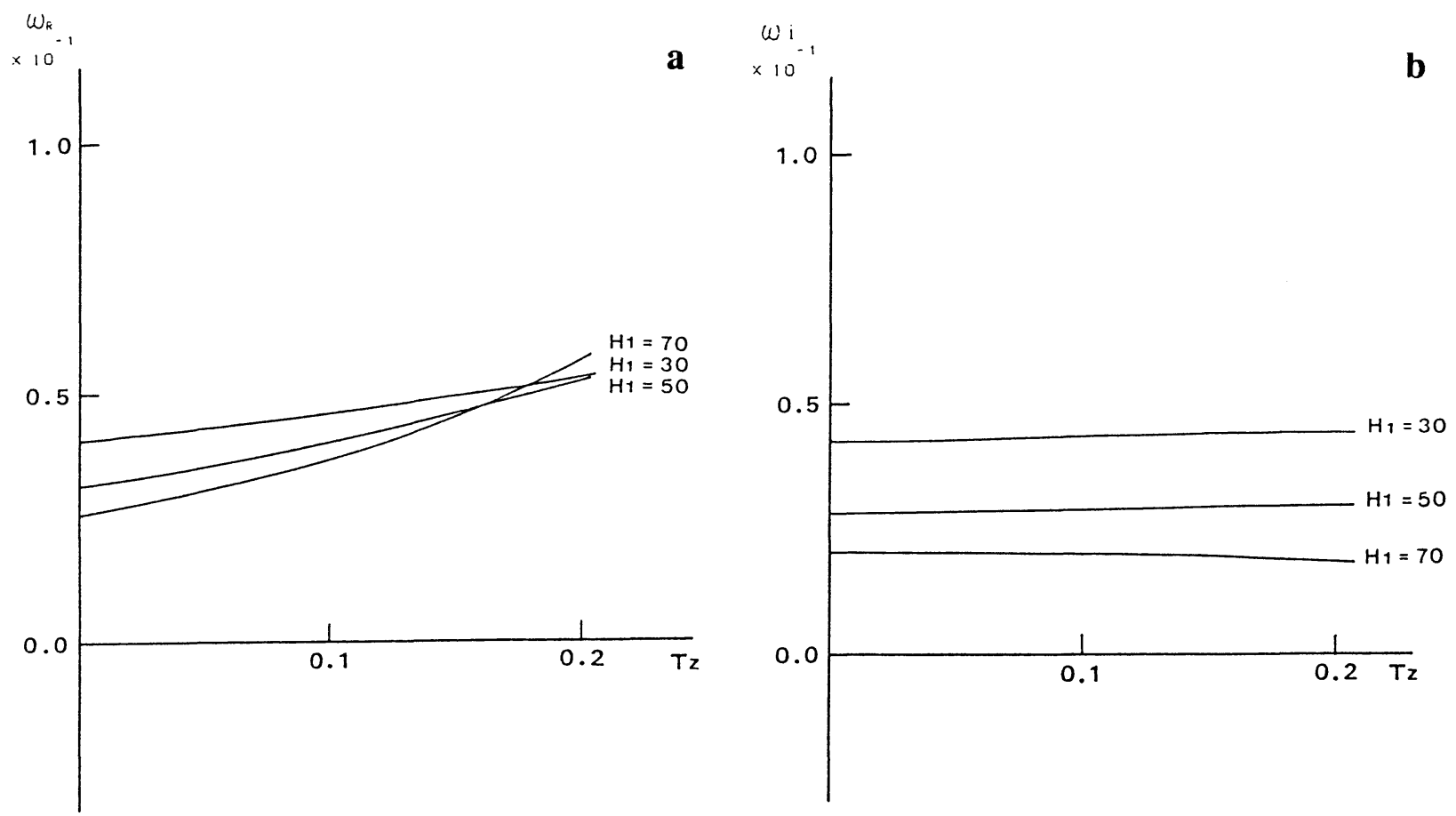

Fig. 10. Frequency (a) and growth rate (b) for several surface layers depths $\left(H_{1}=30,50\right.$ and $\left.70 \mathrm{~m}\right)$ as a function of the vertical stratification parameter $T z$. 
Research from the Japanses Ministry of Education, Science and Culture. The numerical computations were performed with the use of the FACOM M3500 computer at Tokai University.

\section{Reference}

Anderson D.L.T. and J.P. McCreary, 1985: Slowly propagating disturbances in a coupled oceanatmosphere model. J. Atmos. Sci., 42, 615-629.

Barston A.G., 1987: The global climate for March-May 1986: continued uncertainty about the possible onset of an ENSO episode. Mon. Wea. Rev., 115, 317-335.

Bergman K.H., 1987: The global climate of SeptemberNovember 1986: A model ENSO warming develops in the tropical Pacific. Mon. Wea. Rev. 115., 2524-2541.

Bjerknes J., 1969: Atmospheric teleconnections from the equatorial pacific. Mon. Wea. Rev., 97, 163173.

Cane M.A., S.E. Zebiak and S.C. Dolan, 1986: Experimental forecasts of El Niño. Nature, 321, 827-832.

Gill A.E. and E.M. Rasmusson, 1983: The 1982-83 climate anomaly in the equatorial pacific. Nature, 306, 229-234.

Gill A.E., 1985: Elements of coupled ocean-atmosphere Models, J.C.J. Nihoul, Ed., Elsevier Oceanography
Series, 40, Elsevier, 303-327.

Hirst A.C., 1985: Free equatorial instability in simple coupled atmosphere-ocean models. Coupled OceanAtmosphere Models. J.C.J. Nihoul, Ed., Elservier Oceanography Series, 40., 153-165.

Hirst A.C., 1986: Unstable and damped equatorial models in simple coupled ocean-atmosphere models. J. Atmos. Sci., 43 606-630.

Nitta, T. and T. Motoki, 1987: Abrupt enhancement of convective activity and low-level westerly burst during the onset phase of the 1986-87 El Niño. J. Meteor. Soc. Japan, 65, 373-390.

Philander S.G.H., T. Yamagata and R.C. Pacanowski., 1984: Unstable air-sea interactions in the tropics. J. Atmos. Sci. 41, 604-613.

Rennick, M.A., 1983: A model of atmosphere-ocean coupling in El Niño. Science, 222, 1189-1195.

Yamagata, T., 1985: Stability of a simple air-sea coupled model in the tropics. Coupled OceanAtmosphere Models. J.C.J. Nihoul, Ed., Elservier Oceanography Series, 40., 153-165.

Zebiak, S.E., 1984: Tropical atmosphere-ocean interaction and the El Niño/Southern Oscillation phenomenon. Ph. D. thesis, M.I.T., 261pp.

Zebiak, S.E. and M.A. Cane, 1987: A model El NinoSouthern Oscillation. Mon. Wea. Rev. 115, 22622278 .

\section{海洋境界層を含む単純大気海洋結合モデルの不安定問題 \\ 和方吉信 \\ (東海大学海洋学部海洋工学科)}

エル・ニーニヨ現象を説明するために、いくつかの単純大気海洋結合モデルが提唱されている。とてで は、ゼビヤックとケイン (1987) が提唱した、海洋の上層に境界層を含む大気海洋結合モデルの安定性を、 固有值問題を解いて調べた。このモデルも、ハースト (1986) モデルに現れる解に似た東進する不安定モー ドがあるととが分かった。安定性は、混合層の深度に強く依存していた。混合層の深い西太平洋では、大 気海洋結合係数（過熱パラメーター）を増加しても不安定モードは現れないが、中央太平洋では東進する 不安定モードが容易に現れる。また、境界層を考慮に入れたてのモデルでは移流モデル（Gill タイプ）の 極限ではケルビンモードも不安定化した。 